\title{
REVIEW
}

\section{Bone fragility in patients with chronic kidney disease}

\author{
Martine Cohen-Solal' ${ }^{1}$, Thomas Funck-Brentano ${ }^{1}$ and Pablo Ureña Torres ${ }^{2,3}$ \\ 'Department of Skeletal Diseases, INSERM U1132 \& Université de Paris, Hôpital Lariboisière, Paris, France \\ ${ }^{2}$ AURA Nord, Saint Ouen, France \\ ${ }^{3}$ Department of Renal Physiology, Necker Hospital, Université de Paris, Paris, France
}

Correspondence should be addressed to M Cohen-Solal: martine.cohen-solal@inserm.fr

\begin{abstract}
Mineral and bone diseases (MBD) are predominant in patients with chronic kidney disease (CKD) and lead to several bone manifestations, from pain to skeletal fractures. Cumulative traditional clinical risk factors, such as age and gender, in addition to those related to CKD, enhance the risk of comorbidity and mortality related to fractures. Despite great advances in understanding MBD in CKD, clinical and biological targets are lacking, which leads to under-management of fractures. Optimal PTH control results in a net improvement in defining the levels of bone remodeling. In addition, circulating biomarkers such as bonespecific alkaline phosphatase and cross-linked collagen type I peptide will also provide additional information about remodeling rate, bone mineralization and the evaluation of fracture risk. Imaging techniques identify patients at risk by measurement of bone mineral density by DEXA or by high peripheral QCT, which allow the discrimination of trabecular and cortical bone. Here, we have reviewed the literature related to epidemiology and the pathophysiological role of mineral and biochemical factors involved in CKD-MBD with a special focus on fracture risk. We also provide an algorithm that could be used for the management of bone diseases and to guide treatment decisions. Finally, the combined expertise of clinicians from various disciplines is crucial for the best prevention of fractures.

Key Words

- bone

- skeleton

- fracture

- bone mineral density

- CKD-MBD

- phosphate

- calcium

- parathyroid hormone

- vitamin D
\end{abstract}

\section{Introduction}

Chronic kidney disease (CKD) is associated with a high morbidity and mortality, in which skeletal complications are predominant. Mineral and bone diseases (MBD) observed in CKD are now joint entities called CKD-MBD, which refers to clinical events related to calcium and phosphate metabolism such as fractures, biochemical abnormalities and cardiovascular events like vascular calcifications (1). The mineral disorders were added to the previous so-called renal osteodystrophy (ROD) which was previously based on bone biopsies. Indeed, several features of bone strength which are also linked to mineral metabolism are currently included, such as bone structure, mineralization and level of bone remodeling that contribute to the estimation of fracture risk. Therefore, coupling mineral disorders to specific bone features highlight CKD-MBD as a whole entity with dependent and complex interactions. Skeletal fractures are the main clinical outcome in CKD, the prevention of which remain a challenge until now. In addition to a high mortality rate, costs related to hospitalization for fractures in dialysis patients increases the economic burden of bone disease $(2,3,4,5,6)$. We will here describe the diagnosis tools available and their additional value for treatment decisions (Fig. 1).

\section{Epidemiology of skeletal fractures in CKD}

The management of CKD has greatly improved in the last few decades, allowing a longer life expectancy
This work is licensed under a Creative Commons Attribution-NonCommercial 4.0 International License. ded from Bioscientifica.com at 04/26/2023 12:51:08PM 
Strategy to evaluate bone fragility in CKD

\begin{tabular}{|l|}
\hline Clinical risk factors \\
\hline - Age, Gender \\
- History of fracture \\
- Glucocorticoids \\
- Diabetes and \\
cardiovascular diseases \\
- Frax analysis with or \\
without BMD \\
\hline
\end{tabular}

\begin{tabular}{|l|}
\multicolumn{1}{|c|}{ Serum biomarkers } \\
\hline - Mineral tests : \\
- calcium - Phosphate \\
- PTH - 25OH Vitamin D \\
- Bone turnover: \\
- bone specific alkaline \\
phosphatase - CTX \\
\hline
\end{tabular}

\begin{tabular}{|l|}
\multicolumn{1}{|c|}{ Bone imaging } \\
\hline - Standard X-Rays for the \\
evaluation of vertebral or long \\
bone fractures \\
- BMD measured by DEXA <- \\
2.5 T-score \\
- HRpQCT to measure the \\
bone microarchitecture for \\
research purposes
\end{tabular}

\section{Figure 1}

Tools available to assess bone fragility. A combination of clinical factors, bone and mineral biomarkers as well as imaging are required to characterize the profile of fragility and help to guide treatment decisions. and a reduction of subsequent age-related bone loss. Longitudinal studies have extensively reported the incidence of fractures in patients with CKD $(4,7$, $8,9)$. Most of these studies found that incidence is progressively increased with CKD stage (10). The risk of skeletal fracture is up to five times higher in individuals with an estimated glomerular filtration rate (eGFR) below 15, compared to individuals with eGFR above $60 \mathrm{~mL} / \mathrm{min} / 1.73 \mathrm{~m}^{2}$. Other factors such as age above 65 years and gender play a major role in fracture occurrence (11). The Dialysis Outcomes and Practice Patterns Study (DOPPS) reported an incidence of fractures significantly higher in patients in hemodialysis than in the general population, as well as a 3.7-fold increased risk of death (5). Hence, incidence of hip fractures is four-fold higher in patients in dialysis therapy than in the general population even after adjustment for age, gender and ethnicity (7, 12). The incidence of hip fracture is three times higher in Caucasian than in African American patients with CKD (2) and two times higher in women than in men with CKD (4, 9 , 13). Other clinical risk factors include older age, low BMI and a long history of dialysis. As for non-CKD patients, an history of prior fracture is also highly associated with increased risk of hip fracture (14). US Medicare data collected in hemodialysis patients identified downward hip-fracture incidence trends from 2000 to late 2009 (2), although most prominent in older adults of both genders (15). Indeed, the incidence of hip fracture increased when dialysis treatment was initiated from 1996 to 2004 and then declined until 2009, although it remained higher than in 1996 (16). A high relative risk of hip fractures begins at an age of 55 years and remains high, particularly in CKD patients with high bone turnover disease rather than with low turnover $(7,17)$. The mortality risk after a hip fracture is increased for CKD patients on dialysis
$(18,19)$ but surprisingly has essentially not changed after 1998 for either sex (20). These data illustrate that the risk of skeletal fractures combines the classical risk factors observed in the non-CKD population in addition to those related to CKD. After 4 years of dialysis, the agestandardized incidence ratio was 9.83 for men and 8.10 for women (7). Moreover, 30 days after a hip fracture, mortality risk reached $16 \%$ when dialysis is initiated after the age of 67 years (16) and hip fracture-related mortality risk is two times higher when eGFR is below 45 compared to when above $45 \mathrm{~mL} / \mathrm{min} / 1.73 \mathrm{~m}^{2}$ (21). Using the French National Database in 2010, we found significantly higher mortality rates after hip fracture in dialysis patients, reaching $12 \%$ in men and $8 \%$ in women, along with a longer hospital stay in the intensive care unit (4). Several associated risk factors are identified, including vascular-related diseases, diabetes and dementia. The prevalence of vertebral fractures remains unknown, as it has been poorly reported in cohorts and dialysis registers. The prevalence is low, ranging from $7 \%$ to $20 \%$ $(22,23)$, although these might be underestimated since spinal X-rays are not performed on a routine basis. Casecontrol studies with a small number of HD patients on hemodialysis demonstrated that a low BMD at the lumbar spine is associated with vertebral fracture risk and with prevalent or self-reported peripheral fractures (24). In contrast, it is noteworthy that lumbar spine BMD does not have the same predictive value as demonstrated in the absence of CKD. In a meta-analysis of 13 studies (25), only one study mentioned the presence of vertebral fracture in relation to dialysis, finding no association between risk of fracture and BMD. The 2017 KDIGO (Kidney Dialysis Improving Global Outcomes) guidelines recommended the measurement of BMD in patients with stage $3 \mathrm{a}-5 \mathrm{D}$ CKD for predicting peripheral fractures. 


\section{Assessment of fracture risk in CKD-MBD}

The KDIGO working group recommended the use of the same World Health Organization (WHO) definition for osteoporosis in CKD patients as advocated for the general population. This definition remains suitable for the diagnosis of stages 1-3a CKD. In contrast, in bone disease stages $3 \mathrm{~b}$ to $5-5 \mathrm{D}$, CKD patients show a larger spectrum of phenotypes in relation to BMD. There is no relationship between the type of bone disease and BMD because of additional mineral changes in CKD. Indeed, low BMD might be due to a low bone mass or to mineralization defects that are more frequent in CKD than in non-CKD patients. Therefore, the accurate characterization of the underlying bone disease by bone and mineral tools is recommended to achieve accurate diagnosis and define a specific treatment.

\section{Bone histology}

Bone histomorphometry is the gold standard to determine the bone abnormalities of CKD-MBD (26). This is not routinely performed because of the invasive nature and the scarcity of facilities for the analysis of bone biopsies. Most patients with CKD stages 3-5 are expected to have histological signs of high bone turnover in whom more than $80 \%$ have increased serum PTH level $(13,27)$. Other reports showed histological high bone turnover in $47.2 \%$ of patients with CKD stages 3-4 and in $61.4 \%$ with CKD stage 5 (28). However, more recent studies showed lowturnover bone diseases in two small populations with predialysis and a wide eGFR range $\left(<5\right.$ to $\left.90 \mathrm{~mL} / \mathrm{min} / 1.73 \mathrm{~m}^{2}\right)$ $(29,30)$ and in most CKD patients on dialysis $(17,31)$. These controversial results are due to the recruitment bias of biopsy-based studies, since bone biopsies are mainly performed in symptomatic patients or in the context of clinical trials, but not for epidemiological purposes. The histological bone profile of patients with fractures is still lacking.

\section{Bone mineral density}

BMD provides the major contribution for the assessment of fracture risk. In non-CKD patients, the reduction of one S.D. in BMD as measured by dual-energy $\mathrm{x}$-ray absorptiometry (DEXA) doubles the fracture risk and is therefore a major parameter to evaluate bone fragility. The major limitations are spinal affections such as scoliosis or lumbar osteoarthritis as well as vascular calcifications that lead to the overestimation of BMD. These conditions are particularly frequent in CKD patients. A meta-analysis revealed that BMD is lower in pre-dialysis and dialysis CKD patients with fractures than without fractures (25). However, the results of four prospective cohorts showed good predictive value of BMD for risk of fracture with CKD stages 3-5D $(26,32)$; BMD measurement is therefore recommended in CKD. The FRAX tool is also valuable in predicting peripheral fractures in older patients with CKD stages $2-5$ because of the major contribution of the clinical risk factors (33). Altogether, low BMD is a risk factor for fracture, but this might not be sufficient to initiate a bone-specific treatment as in non-CKD patients because of mineralization defects. TBS is a new method based on a gray-level textural index derived by an algorithm that analyzes the spatial organization of pixel intensity from lumbar spine DEXA images. TBS provides information about bone microarchitecture and predicts fractures independently of major clinical risk factors or real BMD measurements (34). In a cohort of 1426 participants followed for a mean of 4.7 years, including 199 with eGFR $<60 \mathrm{~mL} / \mathrm{mn} / 1.73 \mathrm{~m}^{2}$, low TBS score was independently associated with increased fracture risk in adults with reduced kidney function (35).

\section{High-resolution peripheral quantitative CT (HR-pQCT) measurement}

BMD measurement by DEXA alone is insufficient to assess fracture risk because of a weak discriminating power of DEXA to assess cortical and trabecular bone. In CKD, lowbone turnover is associated with thin cortices with normal cortical porosity, while high bone-turnover diseases reveal high cancellous bone volume and normal cortical thickness (17). Accordingly, altered cortical bone structure contributes to bone fragility in CKD (36). Measure of architecture using HRpQCT showed early impairment of trabecular bone, before the onset of severe secondary hyperparathyroidism in CKD stages 2-4. In addition, bone loss observed in patients with CKD stage 5D affected cortical BMD and thickness, but not trabecular bone, and is correlated with dialysis length and serum PTH level (36). However, levels of neither calciotropic hormones such as PTH nor bone remodeling markers were associated with changes in trabecular density, number and heterogeneity. These findings suggest that imaging appendicular skeleton provides a better estimate of cortical bone loss that is strongly associated with fractures in CKD (37). This technique is only available for research purposes.
This work is licensed under a Creative Commons Attribution-NonCommercial 4.0 International License. ded from Bioscientifica.com at 04/26/2023 12:51:08PM 


\section{Bone biomarkers}

In the general population, bone biomarkers are useful tools to estimate bone remodeling, to predict bone loss and the response to treatment. They provide a good quantification of the activity of bone cells at the total body level. Among the bone cell-derived factors, those secreted by osteoclasts are bone resorption markers, while those produced by osteoblasts or osteocytes provide insight into bone formation. In CKD, the significance of bone markers may be close to the PTH levels, but also provide additional specific information about the regulation of bone remodeling. Bone specific markers are required because the relationship between PTH and bone biomarkers is not fully consistent in clinical practice. Hence, low bone turnover could be observed in the presence of high PTH levels because of the down-regulation of PTH receptors, previously called PTH resistance. A previous study based on bone biopsy revealed that patients with high bone turnover also have higher plasma bone specific alkaline phosphatase (BSAP) levels than patients with normal or low bone turnover and levels above the threshold of $20 \mathrm{ng} / \mathrm{mL}$. Combination of high plasma alkaline phosphatase with high PTH showed a good predictive value for the diagnosis of high-turnover bone disease (38). In addition, there are tight correlations between total serum alkaline phosphatase level and hip fracture risk and mortality in dialysis patients (39). Additional bone biomarkers are now available, such as cross-linked collagen type I peptide (CTX) and TRAP-5b for bone resorption and BSAP, sclerostin, and procollagen type $1 \mathrm{~N}$-terminal propeptide (P1NP) for bone formation (36). A more recent study revealed that BSAP, P1NP and TRAP5b were highly correlated to the level of bone remodeling assessed by bone biopsies as well as to the cortical thickness assessed by HRpQCT (40). Therefore, because of the additional value of bone biomarkers, we suggest that these measurements should be included in the evaluation of bone remodeling and fracture risk in CKD.

\section{Circulating factors of mineral metabolism}

PTH is the major surrogate biomarker for bone fragility. Most CKD patients with adynamic bone disease show serum intact PTH level $<150 \mathrm{pg} / \mathrm{mL}$ (41) and those with histological SHPT show PTH level $>600 \mathrm{pg} / \mathrm{mL}$ (42). Cohorts demonstrated that both high and low circulating PTH levels are associated with high hip-fracture incidence $(6,14,43)$. Indeed, low PTH level was associated with fracture incidence (44), while the highest serum PTH level was associated with the highest prevalence of fractures in the DOPPS cohort $(5,6,14,45)$. Additionally, fractures strongly increase the risk of all-cause and cardiovascular mortality, particularly in patients $\geq 45$ years old as compared with younger patients (43). Accordingly, timedependent PTH increase is closely associated with dialysis length, and relative hypoparathyroidism (PTH level $<200 \mathrm{pg} / \mathrm{mL}$ ) is independently associated with increased mortality risk in CKD stage 5D (46). Others have shown that a serum PTH level measured before a new fracture was associated with a significantly increased risk of fracture, in contrast to a baseline or time-averaged PTH level. The upper and lower PTH values of the U-shaped PTH curve are associated with a significantly increased risk of fracture as compared with PTH values within the recommended NKF/K-DOQI target values. Therefore, recommendations are to consider a persistent or progressively increase PTH level, considering a trend of PTH levels within the previous months rather than based on a single elevated PTH level. Various confounding factors may interfere with the interpretation of PTH level at the time of a new fracture and do not take into account factors such as previous parathyroidectomy or calcimimetics in patients with a long history of uncontrolled SHPT. Hence, long-term exposure to high serum PTH levels induced a preferential loss of cortical bone and enhanced the risk of fracture, which could be even more pronounced in CKD stage-5D women (47). Accordingly, parathyroidectomy reduces bone turnover, improves BMD and reduces long-term risk for fractures, as observed in CKD stage 5D patients $(48,49,50)$.

\section{The phosphate/FGF23/Klotho axis}

The skeleton is the main storage site and one of the most important physiologic regulators of calcium and phosphate metabolism, together with the kidney. In bone, low extracellular phosphate concentration is crucial for apoptosis of mature chondrocytes in the growth plate and the cascade of events leading to normal bone growth such as blood vessel invasion and mineralization (51). Abnormal serum phosphate level is undeniably one of the major components of CKD-BMD. Circulating phosphate level slowly increases as CKD progresses and directly and indirectly contributes to the skeletal fragility found in CKD-MBD, particularly via the stimulation of PTH and FGF23 production (52). Serum FGF23 levels significantly increase with CKD stage 1-5 earlier than the PTH level. FGF23, produced by osteocytes and osteoblasts, regulates physiological functions of the kidney, stimulates urinary phosphate excretion and inhibits calcitriol synthesis 
after binding a complex formed by alpha-klotho and is one of the four canonical FGF receptors. FGF23 also controls the bone mineralization process. The lack of FGF23 (as in FGF23-knockout mice) and the excess of FGF23 (as in klotho-knockout mice) results in severe bone demineralization. However, in CKD stage 5D patients, BMD is not correlated with serum FGF23 level (53). High FGF23 level has been associated with reduced osteoid thickness and osteoid maturation time, in children with normal renal function and in CKD children on dialysis (54). This enigma appears to be deciphered because FGF23 modulates bone mineralization by regulating tissue nonspecific alkaline phosphatase (TNALP) specifically via FGFR23 and independent of klotho. FGF23 inhibits TNALP, which thereby increases the extracellular concentration of pyrophosphate, reduces the amount of inorganic (free) phosphorus and indirectly stimulates expression of osteopontin, a known mineralization inhibitor (55). Excessive FGF23 level also contributes to bone loss in CKD via another klotho-dependent mechanism and the stimulation of the osteoblast Wnt inhibitors Dkk1 (56). Therefore, inactivation of the Wnt/b-catenin signaling pathway by the altered phosphate/FGF23/Klotho axis may provide another autocrine/paracrine mechanism favoring bone loss in CKD-MBD.

\section{Bone strength}

The available tools described above show that each of them provide specific information on several aspects of bone strength. This further provides an insight into the complexity of bone diseases in CKD, likely because of additional uremic-related mineral disorders that affect bone strength. From a clinical point of view, the final result of the quality of bone is the resistance to fracture. Therefore, tests which quantify fracture resistance are still missing. Further research developments are requested, in particular toward a better understanding of the impact of CKD in different aspects of bone resistance, and among them matrix production and quality, the role played by the bone microenvironment and the contribution of uremic factors.

\section{Management of mineral disorders and fracture in CKD}

Since the incidence of fracture is high in CKD patients, the prevention of bone and mineral events are crucial and should be a challenge for the different experts involved in patient management. Several guidelines to prevent fractures could be also applied to CKD patients. Falls is a major determinant of fracture that could be prevented, although high incidence of falls is not fully documented in CKD. Factors associated with falls such as low muscle function could be prevented by programs based on exercise in rehabilitation settings with the aim of promoting muscle strength and equilibrium. Denutrition is a factor significantly associated in CKD in dialyzed men with hip fractures (4). Special attention should be paid to adequate food intake in this context. The prevention strategy should be particularly oriented in the elderly, in whom age comes in addition to mineral disorders. Overall, the correction of serum mineral disorders from the beginning of the decline of kidney function remains a major goal to reduce the comorbidities observed in CKD-MBD.

The pharmacological management of osteoporotic fractures or low bone density to prevent fractures in CKD stage 1-3b does not differ from that in osteoporosis without CKD because of persistent kidney function. When eGFR is above $30 \mathrm{~mL} / \mathrm{mn}$, the main anti-fracture medications such as raloxifene, bisphosphonates and teriparatide (the human recombinant PTH) will follow the same recommendations as in non-CKD patients. Until recently, the treatment of CKD stage 4-5D patients with osteoporosis, that is, low bone mass or fractures remained a challenge. A more recent drug offered new opportunities. Denosumab at the dose of $60 \mathrm{mg}$ prescribed for the prevention of fracture in patients at high risk is allowed in CKD, which provided a new hope to treat CKD patients with fractures. However, such a prescription cannot be based only in low bone density in CKD because T-score $<-2.5$ is not synonymous of osteoporosis in these patients. We therefore recommend to first consider patients with severe fragility fracture, in whom bone strength is impaired.

Management of CKD-related fractures should primarily identify the cause because osteomalacia and osteoporosis require specific treatment. Since the type of bone disease could be predicted by the combination of both bone and mineral biomarkers $(38,40)$, we here propose an algorithm based on the serum levels of PTH, alkaline phosphatase and calcium levels (Fig. 2). In patients with high serum PTH level, cinacalcet should be proposed as it has been shown to reduce fracture rate in older dialysis patients with SHPT (57). In case of resistance to cinacalcet, a parathyroidectomy should be considered.

Low PTH levels could evoke osteomalacia or adynamic bone disease. Osteomalacia is suggested by low serum $25 \mathrm{OHD}$, low total calcium or phosphate level in addition

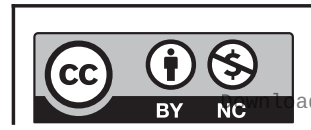

This work is licensed under a Creative Commons Attribution-NonCommercial 4.0 International License. ded from Bioscientifica.com at 04/26/2023 12:51: 08PM 


\section{CKD stage 4-5-5D and severe fractures \\ (vertebrae, femur, humerus, pelvis)}

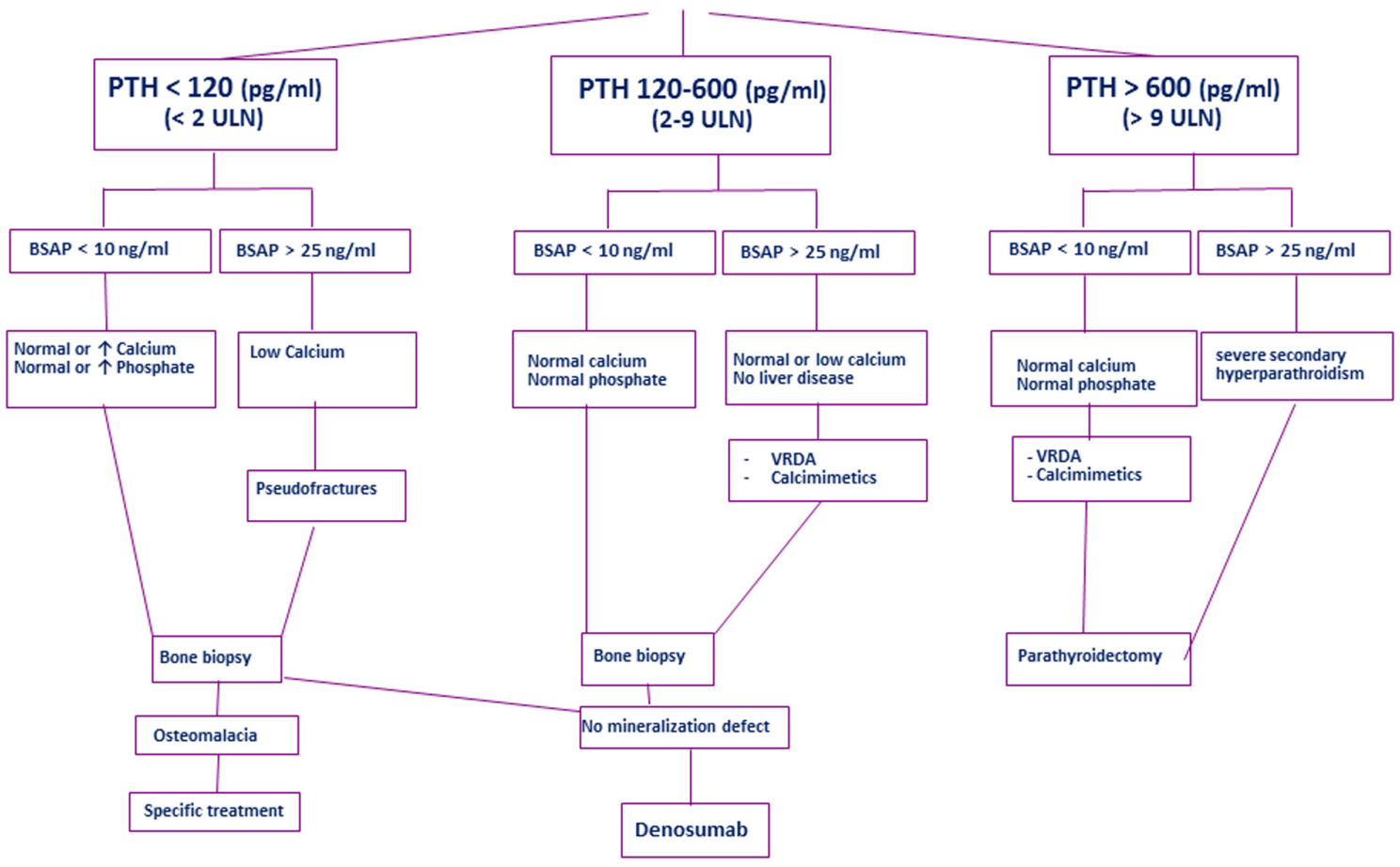

Figure 2

Proposed algorithm for treatment decision in patients with CKD and fracture. Treatment decisions are dependent of the levels of parathyroid hormone (PTH) and bone specific alkaline phosphatase (BSAP) levels. The different conditions are shown, to guide treatment decisions appropriately.

to high alkaline phosphatase levels. There are no biological or imaging markers that discriminate between the two bone profiles. Therefore, we recommend a bone biopsy because of the requirement of specific treatment such with native vitamin $\mathrm{D}$ or phosphate supplementation. In the presence of low PTH levels and normal mineral levels, a bone biopsy is recommended before treatment to document the absence of mineralization defect and the persistence of bone cells before treatment.

Most anti-osteoporosis treatments are contraindicated with eGFR below the threshold of $30 \mathrm{~mL} / \mathrm{mn}$. Bisphosphonates accumulate in bone tissues regardless of kidney function, but reduced renal clearance promotes high accumulation. This is associated with defective bone mineralization and osteomalacia (58) or might favor an adynamic bone disease. For this reason, the use of bisphosphonates in CKD stage 4 and 5 is not recommended. Further, no trial addresses the absence of toxicity, nor the efficacy of these drugs for preventing fracture in CKD. Few studies and early post-hoc analyses assessed the effect of bisphosphonates on BMD and on circulating mineral and bone biomarkers, but did not have sufficient power to predict fracture risk. A recent systematic review also provides no clear evidence that these treatments could be helpful in CKD (59). Recently, denosumab, an anti-RANKL biologic therapy, offered a new avenue for managing fractures. Treatment with denosumab is associated with reduced risk of vertebral, non-vertebral and hip fractures in osteoporotic women (60). In a subgroup of 73 women with CKD stage 4, denosumab $60 \mathrm{mg}$ increased the BMD in a similar manner in women with CKD stages $1-3$, but the low number of patients prevented demonstration of an effect in fracture prevention (61). In patients with CKD stages 4-5D with severe secondary hyperparathyroidism, denosumab induced a marked hypocalcemia and an increased PTH level within 15 days. Therefore, close monitoring is required during the first few weeks in patients with advanced CKD. Recently, a trial compared the 1-year effect of denosumab to alendronate in dialysis patients with low PTH and found a better increase in BMD and improvement of bone biomarkers (62). Because of the non-linear relation between BMD and fracture risk in $\mathrm{CDK}$, this increase in BMD does not fully secure fracture risk reduction in the short or long term. Further trials are needed to test the effect of such a medication in both BMD and fracture.
This work is licensed under a Creative Commons Attribution-NonCommercial 4.0 International License. ded from Bioscientifica.com at 04/26/2023 12:51:08PM via free access 


\section{Conclusion}

In conclusion, the high incidence of fractures and mortality in patients with CKD require the use of the combination of available tools for evaluating fracture. Because of the complexity of bone fragility in CKD, a multidisciplinary management approach which includes nephrologists and bone experts in CKD-MBD is required before the initiation of anti-resorption or bone anabolic treatments.

\section{Declaration of interest}

The authors declare that there is no conflict of interest that could be perceived as prejudicing the impartiality of this review.

\section{Funding}

This work did not receive any specific grant from any funding agency in the public, commercial or not-for-profit sector

\section{Author contribution statement}

All the co-authors wrote and reviewed the manuscript, and approved the final version.

\section{References}

1 Kidney Disease: Improving Global Outcomes (KDIGO) CKD-MBD Work Group. KDIGO clinical practice guideline for the diagnosis, evaluation, prevention, and treatment of chronic kidney diseasemineral and bone disorder (CKD-MBD). Kidney International Supplements 200976 (Supplement 113) S1-S130. (https://doi org/10.1038/ki.2009.188)

2 Beaubrun AC, Kilpatrick RD, Freburger JK, Bradbury BD, Wang L \& Brookhart MA. Temporal trends in fracture rates and postdischarge outcomes among hemodialysis patients. Journal of the American Society of Nephrology 201324 1461-1469. (https://doi.org/10.1681/ ASN.2012090916)

3 Hansen D, Olesen JB, Gislason GH, Abrahamsen B \& Hommel K. Risk of fracture in adults on renal replacement therapy: a Danish national cohort study. Nephrology Dialysis Transplantation 201631 1654-1662. (https://doi.org/10.1093/ndt/gfw073)

4 Maravic M, Ostertag A, Torres PU \& Cohen-Solal M. Incidence and risk factors for hip fractures in dialysis patients. Osteoporosis International 201425 159-165. (https://doi.org/10.1007/s00198-0132435-1)

5 Tentori F, McCullough K, Kilpatrick RD, Bradbury BD, Robinson BM, Kerr PG \& Pisoni RL. High rates of death and hospitalization follow bone fracture among hemodialysis patients. Kidney International 2014 85 166-173. (https://doi.org/10.1038/ki.2013.279)

6 Danese MD, Kim J, Doan Q V., Dylan M, Griffiths R \& Chertow GM. PTH and the risks for hip, vertebral, and pelvic fractures among patients on dialysis. American Journal of Kidney Diseases 200647 149-156. (https://doi.org/10.1053/j.ajkd.2005.09.024)

7 Alem A, Sherrard D, Gillen D, Weiss N, Beresford S, Heckbert S, Wong C \& Stehman-Breen C. Increased risk of hip fracture among patients with end-stage renal disease. Kidney International $20005 \mathbf{8}$ 396-399. (https://doi.org/10.1046/j.1523-1755.2000.00178.x)

8 Wakasugi M, Kazama JJ, Taniguchi M, Wada A, Iseki K, Tsubakihara Y $\&$ Narita I. Increased risk of hip fracture among Japanese hemodialysis patients. Journal of Bone and Mineral Metabolism 2013

31 315-321. (https://doi.org/10.1007/s00774-012-0411-z)

9 Nickolas TL, McMahon DJ \& Shane E. Relationship between moderate to severe kidney disease and hip fracture in the United States. Journal of the American Society of Nephrology $2006 \mathbf{1 7}$ 3223-3232. (https://doi.org/10.1681/ASN.2005111194)

10 Naylor KL, Garg AX, Zou G, Langsetmo L, Leslie WD, Fraser LA, Adachi JD, Morin S, Goltzman D, Lentle B, et al. Comparison of fracture risk prediction among individuals with reduced and normal kidney function. Clinical Journal of the American Society of Nephrology 201510 646-653. (https://doi.org/10.2215/CJN.06040614)

11 Naylor KL, McArthur E, Leslie WD, Fraser LA, Jamal SA, Cadarette SM, Pouget JG, Lok CE, Hodsman AB, Adachi JD, et al. The three-year incidence of fracture in chronic kidney disease. Kidney International 201486 810-818. (https://doi.org/10.1038/ki.2013.547)

12 Maravic M, Ostertag A, Urena P \& Cohen-Solal M. Dementia is a major risk factor for hip fractures in patients with chronic kidney disease. Osteoporosis International 201627 1665-1669. (https://doi org/10.1007/s00198-015-3429-y)

13 Moranne O, Froissart M, Rossert J, Gauci C, Boffa J-J, Haymann JP, $\mathrm{M}^{\prime}$ rad MB, Jacquot C, Houillier P, Stengel B, et al. Timing of onset of CKD-related metabolic complications. Journal of the American Society of Nephrology 200920 164-171. (https://doi.org/10.1681/ ASN.2008020159)

14 Jadoul M, Albert JM, Akiba T, Akizawa T, Arab L, Bragg-Gresham JL, Mason N, Prutz KG, Young EW \& Pisoni RL. Incidence and risk factors for hip or other bone fractures among hemodialysis patients in the Dialysis Outcomes and Practice Patterns Study. Kidney International 200670 1358-1366. (https://doi.org/10.1038/ sj.ki.5001754)

15 Wright NC, Saag KG, Curtis JR, Smith WK, Kilgore ML, Morrisey MA, Yun H, Zhang J \& Delzell ES. Recent trends in hip fracture rates by race/ethnicity among older US adults. Journal of Bone and Mineral Research 201227 2325-2332. (https://doi.org/10.1002/jbmr.1684)

16 Nair SS, Mitani A a, Goldstein B a, Chertow GM, Lowenberg DW \& Winkelmayer WC. Temporal trends in the incidence, treatment, and outcomes of hip fracture in older patients initiating dialysis in the United States. Clinical Journal of the American Society of Nephrology 20138 1336-1342. (https://doi.org/10.2215/CJN.10901012)

17 Malluche HH, Mawad HW \& Monier-Faugere MC. Renal osteodystrophy in the first decade of the new millennium: analysis of 630 bone biopsies in black and white patients. Journal of Bone and Mineral Research 201126 1368-1376. (https://doi.org/10.1002/ jbmr.309)

18 Bass E, French DD, Bradham DD \& Rubenstein LZ. Risk-adjusted mortality rates of elderly veterans with hip fractures. Annals of Epidemiology 200717 514-519.(https://doi.org/10.1016/j. annepidem.2006.12.004)

19 Fransen M, Woodward M, Norton R, Robinson E, Butler M \& John Campbell A. Excess mortality or institutionalization after hip fracture: men are at greater risk than women. Journal of the American Geriatrics Society 200250 685-690. (https://doi.org/10.1046/j.15325415.2002.50163.x)

20 Brauer CA, Coca-Perraillon M, Cutler DM \& Rosen AB. Incidence and mortality of hip fractures in the United States. JAMA 20093021573. (https://doi.org/10.1001/jama.2009.1462)

21 Nitsch D, Mylne A, Roderick PJ, Smeeth L, Hubbard R \& Fletcher A. Chronic kidney disease and hip fracture-related mortality in older people in the UK. Nephrology Dialysis Transplantation 200924 1539-1544. (https://doi.org/10.1093/ndt/gfn678)

22 Atsumi K, Kushida K, Yamazaki K, Shimizu S, Ohmura A \& Inoue T. Risk factors for vertebral fractures in renal osteodystrophy. American Journal of Kidney Diseases 199933 287-293. (https://doi.org/10.1016/ S0272-6386(99)70302-1)

23 Ureña P, Bernard-Poenaru O, Ostertag A, Baudoin C, Cohen-Solal M, Cantor T \& de Vernejoul MC. Bone mineral density, biochemical https://ec.bioscientifica.com https://doi.org/10.1530/EC-20-0039 (c) 2020 The authors Published by Bioscientifica Ltd
This work is licensed under a Creative Commons Attribution-NonCommercial 4.0 International License. ded from Bioscientifica.com at 04/26/2023 12:51:08PM 
markers and skeletal fractures in haemodialysis patients. Nephrology Dialysis Transplantation 200318 2325-2331.

24 Jamal SA, Gilbert J, Gordon C \& Bauer DC. Cortical pQCT measures are associated with fractures in dialysis patients. Journal of Bone and Mineral Research 200621 543-548. (https://doi.org/10.1359/ jbmr.060105)

25 Bucur RC, Panjwani DD, Turner L, Rader T, West SL \& Jamal SA. Low bone mineral density and fractures in stages 3-5 CKD: an updated systematic review and meta-analysis. Osteoporosis International 2015 26 449-458.(https://doi.org/10.1007/s00198-014-2813-3)

26 Moe S, Drüeke T, Cunningham J, Goodman W, Martin K, Olgaard K, Ott S, Sprague S, Lameire N, Eknoyan G, et al. Definition, evaluation, and classification of renal osteodystrophy: a position statement from Kidney Disease: Improving Global Outcomes (KDIGO). Kidney International 200669 1945-1953. (https://doi.org/10.1038/ sj.ki.5000414)

27 Levin A, Bakris GL, Molitch M, Smulders M, Tian J, Williams LA \& Andress DL. Prevalence of abnormal serum vitamin D, PTH, calcium, and phosphorus in patients with chronic kidney disease: results of the study to evaluate early kidney disease. Kidney International 2006 71 31-38.(https://doi.org/10.1038/sj.ki.5002009)

28 Lehmann G, Ott U, Kaemmerer D, Schuetze J \& Wolf G. Bone histomorphometry and biochemical markers of bone turnover in patients with chronic kidney disease stages 3-5. Clinical Nephrology 200870 296-305. (https://doi.org/10.5414/CNP70296)

29 Spasovski GB, Bervoets a R, Behets GJ, Ivanovski N, Sikole A, Dams G, Couttenye MM, De Broe ME \& D'Haese PC. Spectrum of renal bone disease in end-stage renal failure patients not yet on dialysis. Nephrology Dialysis Transplantation 200318 1159-1166. (https://doi.org/10.1093/ndt/gfg116)

30 Tomiyama C, Carvalho AB, Higa A, Jorgetti V, Draibe SA \& Canziani MEF. Coronary calcification is associated with lower bone formation rate in CKD patients not yet in dialysis treatment. Journal of Bone and Mineral Research 201025 499-504. (https://doi. org/10.1359/jbmr.090735)

31 Sprague SM, Bellorin-Font E, Jorgetti V, Carvalho AB, Malluche HH, Ferreira A, D'Haese PC, Drüeke TB, Du H, Manley T, et al. Diagnostic accuracy of bone turnover markers and bone histology in patients with CKD treated by dialysis. American Journal of Kidney Diseases 2016 67 559-566. (https://doi.org/10.1053/j.ajkd.2015.06.023)

32 Malluche HH, Davenport DL, Canto T \& Monier-Faugere MC. Bone mineral density and serum biochemical predictors of bone loss in patients with CKD on dialysis. Clinical Journal of the American Society of Nephrology 20149 1254-1262. (https://doi.org/10.2215/CJN.09470913)

33 Jamal SA, West SL \& Nickolas TL. The clinical utility of FRAX to discriminate fracture status in men and women with chronic kidney disease. Osteoporosis International 201425 71-76. (https://doi. org/10.1007/s00198-013-2524-1)

34 McCloskey E V., Odén A, Harvey NC, Leslie WD, Hans D, Johansson H, Barkmann R, Boutroy S, Brown J, Chapurlat R, et al. A meta-analysis of trabecular bone score in fracture risk prediction and its relationship to FRAX. Journal of Bone and Mineral Research 201631 940-948. (https://doi.org/10.1002/jbmr.2734)

35 Naylor KL, Prior J, Garg AX, Berger C, Langsetmo L, Adachi JD, Goltzman D, Kovacs CS, Josse RG \& Leslie WD. Trabecular bone score and incident fragility fracture risk in adults with reduced kidney function. Clinical Journal of the American Society of Nephrology 201611 2032-2040. (https://doi.org/10.2215/CJN.00720116)

36 Nickolas TL, Stein EM, Dworakowski E, Nishiyama KK, KomandahKosseh M, Zhang CA, et al. Rapid cortical bone loss in patients with chronic kidney disease. Journal of Bone and Mineral Research 201328 1811-1820. (https://doi.org/10.1002/jbmr.1916)

37 Cejka D, Patsch JM, Weber M, Diarra D, Riegersperger M, Kikic Z Krestan C, Schueller-Weidekamm C, Kainberger F \& Haas M. Bone microarchitecture in hemodialysis patients assessed by HR-pQCT.
Clinical Journal of the American Society of Nephrology 20116 2264-2271. (https://doi.org/10.2215/CJN.09711010)

38 Ureña P, Hruby M, Ferreira A, Ang KS \& De Vernejoul MC. Plasma total versus bone alkaline phosphatase as markers of bone turnover in hemodialysis patients. Journal of the American Society of Nephrology $19967506-512$

39 Maruyama Y, Taniguchi M, Kazama JJ, Yokoyama K, Hosoya T, Yokoo T, Shigematsu T, Iseki K \& Tsubakihara Y. A higher serum alkaline phosphatase is associated with the incidence of hip fracture and mortality among patients receiving hemodialysis in Japan. Nephrology Dialysis Transplantation 201429 1532-1538. (https://doi. org/10.1093/ndt/gfu055)

40 Salam S, Gallagher O, Gossiel F, Paggiosi M, Khwaja A \& Eastell R. Diagnostic accuracy of biomarkers and imaging for bone turnover in renal osteodystrophy. Journal of the American Society of Nephrology 201829 1557-1565. (https://doi.org/10.1681/ ASN.2017050584)

41 Heaf J. Causes and consequences of adynamic bone disease. Nephron 200188 97-106. (https://doi.org/10.1159/000045968)

42 Behets GJ, Spasovski G, Sterling LR, Goodman WG, Spiegel DM, De Broe ME \& D'Haese PC. Bone histomorphometry before and after long-term treatment with cinacalcet in dialysis patients with secondary hyperparathyroidism. Kidney International 201587 846-856. (https://doi.org/10.1038/ki.2014.349)

43 Lertdumrongluk P, Lau WL, Park J, Rhee CM, Kovesdy CP \& KalantarZadeh K. Impact of age on survival predictability of bone turnover markers in hemodialysis patients. Nephrology Dialysis Transplantation 201328 2535-2545. (https://doi.org/10.1093/ndt/gft290)

44 Yenchek RH, Ix JH, Shlipak MG, Bauer DC, Rianon NJ, Kritchevsky SB, Harris TB, Newman AB, Cauley JA, Fried LF, et al. Bone mineral density and fracture risk in older individuals with CKD. Clinical Journal of the American Society of Nephrology 20127 1130-1136. (https://doi.org/10.2215/CJN.12871211)

45 Fuller DS, Pisoni RL, Bieber BA, Gillespie BW \& Robinson BM. The DOPPS practice monitor for US dialysis care: trends through december 2011. American Journal of Kidney Diseases 201361 342-346. (https://doi.org/10.1053/j.ajkd.2012.10.002)

46 Guh J-Y, Chen H-C, Chuang H-Y, Huang S-C, Chien L-C \& Lai Y-H. Risk factors and risk for mortality of mild hypoparathyroidism in hemodialysis patients. American Journal of Kidney Diseases 200239 1245-1254. (https://doi.org/10.1053/ajkd.2002.33398)

47 Russo CR, Taccetti G, Caneva P, Mannarino A, Maranghi P \& Ricca M. Volumetric bone density and geometry assessed by peripheral quantitative computed tomography in uremic patients on maintenance hemodialysis. Osteoporosis International $1998 \mathbf{8}$ 443-448. (https://doi.org/10.1007/s001980050089)

48 Lu K-C, Ma W-Y, Yu J-C, Wu C-C \& Chu P. Bone turnover markers predict changes in bone mineral density after parathyroidectomy in patients with renal hyperparathyroidism. Clinical Endocrinology 2012 76 634-642. (https://doi.org/10.1111/j.1365-2265.2011.04265.X)

49 Yajima A, Inaba M, Tominaga Y, Nishizawa Y, Ikeda K \& Ito A. Increased osteocyte death and mineralization inside bone after parathyroidectomy in patients with secondary hyperparathyroidism. Journal of Bone and Mineral Research 201025 2374-2381. (https://doi. org/10.1002/jbmr.126)

50 Rudser KD, de Boer IH, Dooley A, Young B \& Kestenbaum B. Fracture risk after parathyroidectomy among chronic hemodialysis patients. Journal of the American Society of Nephrology 200718 2401-2407. (https://doi.org/10.1681/ASN.2007010022)

51 Meleti Z, Shapiro I. \& Adams C. Inorganic phosphate induces apoptosis of osteoblast-like cells in culture. Bone 200027 359-366. (https://doi.org/10.1016/S8756-3282(00)00346-X)

52 Prié D, Torres PU \& Friedlander G. Latest findings in phosphate homeostasis. Kidney International 200975 882-889. (https://doi. org/10.1038/ki.2008.643) https://ec.bioscientifica.com https://doi.org/10.1530/EC-20-0039 (c) 2020 The authors Published by Bioscientifica Ltd

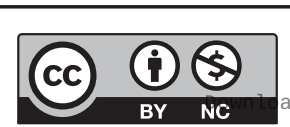

This work is licensed under a Creative Commons Attribution-NonCommercial 4.0 International License. ded from Bioscientifica.com at 04/26/2023 12:51:08PM 
53 Urena Torres P, Friedlander G, de Vernejoul MC, Silve C \& Prié D. Bone mass does not correlate with the serum fibroblast growth factor 23 in hemodialysis patients. Kidney International 200873 102-107. (https://doi.org/10.1038/sj.ki.5002622)

54 Bacchetta J, Cochat P, Salusky IB \& Wesseling-Perry K. Uric acid and IGF1 as possible determinants of FGF23 metabolism in children with normal renal function. Pediatric Nephrology 201227 1131-1138. (https://doi.org/10.1007/s00467-012-2110-3)

55 Murali SK, Roschger P, Zeitz U, Klaushofer K, Andrukhova O \& Erben RG. FGF23 regulates bone mineralization in a 1,25(OH)2D3 and klotho-independent manner. Journal of Bone and Mineral Research 201631 129-142. (https://doi.org/10.1002/jbmr.2606)

56 Carrillo-López N, Panizo S, Alonso-Montes C, Román-García P, Rodríguez I, Martínez-Salgado C, Dusso AS, Naves M \& CannataAndía JB. Direct inhibition of osteoblastic Wnt pathway by fibroblast growth factor 23 contributes to bone loss in chronic kidney disease. Kidney International 201690 77-89.

57 Moe SM, Abdalla S, Chertow GM, Parfrey PS, Block GA, CorreaRotter R, Floege J, Herzog CA, London GM, Mahaffey KW, et al. Effects of cinacalcet on fracture events in patients receiving hemodialysis: the EVOLVE trial. Journal of the American Society of Nephrology 201526 1466-1475. (https://doi.org/10.1681/ ASN.2014040414)
58 Rodd C. Bisphosphonates in dialysis and transplantation patients: efficacy and safety issues. Peritoneal Dialysis International 200121 (Supplement 3) S256-S260. (https://doi.org/10.1177/0896860801021 03S45)

59 Wilson LM, Rebholz CM, Jirru E, Liu MC, Zhang A, Gayleard J, Chu Y \& Robinson KA. Benefits and harms of osteoporosis medications in patients with chronic kidney disease. Annals of Internal Medicine 2017 166 649. (https://doi.org/10.7326/M16-2752)

60 Cummings SR, Martin JS, McClung MR, Siris ES, Eastell R, Reid IR, Delmas P, Zoog HB, Austin M, Wang A, et al. Denosumab for prevention of fractures in postmenopausal women with osteoporosis. New England Journal of Medicine 2009361 756-765. (https://doi. org/10.1056/NEJMoa0809493)

61 Jamal SA, Ljunggren Ö, Stehman-Breen C, Cummings SR, McClung MR, Goemaere S, Ebeling PR, Franek E, Yang YC, Egbuna OI, et al. Effects of denosumab on fracture and bone mineral density by level of kidney function. Journal of Bone and Mineral Research 201126 1829-1835. (https://doi.org/10.1002/jbmr.403)

62 Iseri K, Watanabe M, Yoshikawa H, Mitsui H, Endo T, Yamamoto Y, Iyoda M, Ryu K, Inaba T \& Shibata T. Effects of denosumab and alendronate on bone health and vascular function in hemodialysis patients: a randomized, controlled trial. Journal of Bone and Mineral Research 201934 1014-1024. (https://doi.org/10.1002/jbmr.3676)

Received in final form 20 February 2020

Accepted 13 March 2020

Accepted Manuscript published online 13 March 2020
This work is licensed under a Creative Commons Attribution-NonCommercial 4.0 International License. ded from Bioscientifica.com at 04/26/2023 12:51:08PM 